\title{
¿La memoria encontrada o la memoria inventada? Recursos narrativos y pautas de estilo de índole ficcional o subjetiva en los documentales históricos españoles recientes
}

\author{
Inmaculada SÁNCHEZ AlARCóN \\ Universidad de Málaga (España) \\ inma@uma.es \\ Alejandro JEREZ ZAMBRANA \\ Universidad de Málaga (España) \\ 0617395131@uma.es
}

\begin{abstract}
Resumen
El empleo de los recursos técnicos típicamente asociados a la ficción en la realización de muchas de las cintas documentales producidas en España desde el año 2001 pone de relevancia un cambio conceptual en lo referido a la no-ficción. El reflejo de la Historia a través de la memoria de sus protagonistas es una fórmula que funciona en las producciones más recientes, donde los relatos en primera persona consiguen una identificación colectiva y llegan a un amplio número de espectadores.
\end{abstract}

Palabras Clave: Documental Performativo; memoria histórica; tiempo histórico; tiempo biográfico; fuentes anónimas; narración audiovisual

\section{Memory ecountered or memory invented? Narratives resources and Fictional or Subjective style guidelines in the spanish historical documentaries}

\begin{abstract}
The use of technical resources usually associated with fiction in the realization of many documentary films produced in Spain since 2001 underscores a conceptual change in the non-fiction genre. The image of history through the memory of the main characters is a formula that works in more recent productions, where first-person gets a collective identity and reaches a large number of spectators.
\end{abstract}

Keywords: Performative Documentary; historical memory; historical time; biographical time; anonymous sources; visual storytelling

\section{Referencia normalizada:}

Sánchez Alarcón, I.; Jerez Zambrana, A. (2013) ¿La memoria encontrada o la memoria inventada? Recursos narrativos y pautas de estilo de índole ficcional o subjetiva en los documentales históricos españoles recientes. Historia y Comunicación Social. Vol. 18 Nº Especial Noviembre. Págs. 299-311.

Sumario: 1. Introducción 2. Documentales caracterizados por el uso de recursos narrativos de índole ficcional 3. Las fuentes anónimas y la creación de emociones en la estructura narrativa documental 4. Conclusiones 5. Bibliografía 


\section{Introducción}

Hay muchos fenómenos que resultan significativos de la importancia que ha adquirido la primera persona del singular como forma de comunicación. En un periodo actual que se ha denominado "campaña electoral permanente" (Salmon, 2008: 146), la presencia constante de los políticos en el sistema mediático, por ejemplo, ya no tiene que ver con su función de gestores de la voluntad general. Muy al contrario, el uso preponderante de una retórica performativa en los discursos creados en torno a ellos, que ya no son pertinentes, sino seductores, tiene como fin convertirlos en personajes más cercanos a la ficción que a la realidad. Y no basta más que recordar las veces que el presidente estadounidense Barack Obama, epítome de este fenómeno, ha sido representado como personaje de cómic.

En los documentales, el uso de la primera persona del singular incluso ha dado lugar a dos modalidades específicas, el documental performativo y el documental ensayo, cada vez más presentes en las tendencias de producción a partir de la década de los noventa del pasado siglo. Por mucho que parezca contradictorio, en los documentales de tema histórico, teóricamente más cercanos aún a los discursos de sobriedad que todas las demás manifestaciones de este tipo de relato audiovisual, también es patente el peso que han adquirido la primera persona del singular y todos los recursos relacionados con la subjetividad y la emoción que con ella van asociados.

En este trabajo se ha analizado la existencia de recursos narrativos y pautas de estilo de índole ficcional o intencionalidad subjetiva en los documentales históricos producidos en España a partir de 2001, cuando, con el triunfo de En Construcción (José Luis Guerín, 2001) en el Festival de Cine de San Sebastián, esta modalidad audiovisual adquiere una mayor visibilidad en España.

Se han seleccionado títulos con distribución comercial o que hayan recibido galardones en diferentes festivales de cine celebrados desde esta fecha. Eso sí, hay que tener muy en cuenta también que la mayoría de las producciones de este tipo son difundidos tanto en las salas de cine como en las parrillas de programación. Cada vez resulta más difícil, pues, establecer distinciones entre los planteamientos de los documentales difundidos en salas y el material específicamente concebido para su emisión televisiva.

Pero, antes de realizar este análisis, para entender la orientación de los títulos sometidos a análisis, es preciso entender que las producciones audiovisuales buscan la identificación y el reconocimiento por parte del espectador y, por esta causa, las fuentes utilizadas se orientarán siempre a suscitar esta reacción. Es poco verosímil, pues, que los artífices de un documental sobre cualquier acontecimiento histórico opten por un uso diversificado de los documentos audiovisuales, si eso les puede enajenar la atención de su público potencial. Además, el uso de imágenes conservadas en los archivos resulta caro y, por eso mismo, resulta inaccesible para la mayoría de las producciones. 
Por supuesto, además de los imperativos económicos, habría que añadir la impermeabilidad del mercado audiovisual a las visiones conflictivas de un acontecimiento histórico. En el caso específico del reflejo de la Guerra Civil Española, ya en la Transición, se realizaron algunas producciones documentales que "reactivaron, desde muy distintas perspectivas y posiciones ideológicas, el interés por el análisis de la contienda y sus consecuencias" (Sánchez-Biosca, 2006: 246).

Sin embargo, aunque su discurso cuestiona radicalmente el franquismo, películas como Canciones para después de una guerra o Caudillo, ambas dirigidas por Basilio Martín Patino y estrenadas en 1977 sólo alcanzan a un público con una formación intelectual y una ideología muy determinadas. De hecho, títulos como éstos o documentales prohibidos durante el franquismo, si es que llegan a estrenarse en las salas de proyección comerciales, sólo permanecen durante un tiempo muy corto en la cartelera.

Una vez tenidos en cuenta lo puede condicionar la elaboración de la memoria colectiva en las narraciones de no ficción, vamos a ver que el reflejo de nuestra Historia Contemporánea a través de los documentales más recientes producidos en este país se relaciona con la subjetividad y la invención que, como hemos visto, determinan también otros discursos sociales.

\section{Documentales caracterizados por el uso de recursos narrativos de índole ficcional}

El título de Noticias de una guerra (Eterio Ortega, 2007) parece reafirmar la voluntad referencial del documental en relación con el acontecimiento que refleja, la Guerra Civil Española. Sin embargo, aunque está compuesta casi exclusivamente por imágenes de archivo, sobre todo las dramatizaciones sonoras añadidas en postproducción van a dar a la película una dimensión subjetiva. Los sonidos y voces de actores incluidos de manera asincrónica sirven para añadir fuerza dramática, por ejemplo, en las diferentes secuencias relativas a los bombardeos de ciudades.

Además del montaje, en esta película también se usa la puesta en escena con finalidad cercana a la de la ficción. Destacan las reconstrucciones dramatizadas de los asesinatos del político ultraderechista Calvo Sotelo y del republicano teniente Castillo; de la escritura de una carta por parte del general Mola, la cabeza de la sublevación militar; y del viaje de Franco en el Dragon Rapide desde Canarias para unirse al levantamiento militar.

En estas reconstrucciones, el montaje de contrastes intensifica el efecto de la puesta en escena: por ejemplo, mientras el supuesto locutor de radio cuya narración de los acontecimientos imprime unidad a la narración describe los encierros de San Fermín anteriores a la rebelión del 17 de julio, aparece un primerísimo primer plano de los ojos de Mola al que ya se había visto escribiendo la carta mencionada. Luego, sobre planos de generales de los encierros, se escucha en over la voz que identificamos 
como la del militar especificando que deberán declararse "en rebeldía las divisiones 5,6 y 7 ". Esta contraposición entre imagen y sonido adquiere resonancias ficcionales.

Las reconstrucciones dramatizadas como recurso de puesta en escena también aparecen en Las cajas españolas (Alberto Porlán, 2004), que se centra en los esfuerzos de los republicanos por conservar el patrimonio artístico español durante la contienda. Aquí las reconstrucciones ilustran episodios descritos por la locución como el depósito de varios cuadros del Greco por un alcalde castellano en las cámaras acorazadas del Banco de España, por poner un ejemplo. El objetivo de este recurso es imprimir un mayor dinamismo formal a la narración.

Otros dos casos en los que el elemento ficcional aplicado a la puesta en escena alcanza mayor trascendencia que en el título anterior son La doble vida del faquir (Elisabet Cabeza / Esteve Riambau, 2005) y Mirando al cielo (Jesús Garay, 2008).

La doble vida del faquir habla de una película de aventuras protagonizada por unos niños refugiados que se hizo en un colegio de la provincia de Barcelona en 1937. Entre aquellos niños estaba el padre de Elisabet Cabeza. En varios momentos, la voz en off de la realizadora dirige una especie de carta a su padre muerto cuando ella era pequeña y al que, según dice, ha podido conocer como nunca había imaginado, gracias al descubrimiento de la película y al contacto con sus antiguos compañeros.

Además de por el elemento emocional que aportan la experiencia personal de la directora y secuencias realizadas en espacios desiertos del colegio, alusiones a la memoria que allí dejaron los niños refugiados, la narración adquiere resonancias ficcionales por un recurso estructural: la historia de la película de 1937 y los testimonios de quienes participaron en ella se integran en una estructura circular construida en torno a unos niños que acuden a ver La doble vida del faquir con un hombre mayor, el cineasta Joaquim Jordà, que en la última secuencia aparece disfrazado lo mismo que los pequeños.

Un paso más allá, Mirando al cielo, centrada en los bombardeos italianos que asolaron Barcelona en 1938, hace de la ficción su eje. De hecho, la narración se vehicula a través del punto de vista del personaje de una realizadora de documentales, María, interpretada por la actriz Gabriela Flores, cuyo abuelo defendió la ciudad con una batería antiaérea y que pretende obtener el testimonio de uno de los aviadores italianos que intervinieron en los ataques aéreos, encarnado por Paolo Ferrari. Además, la recreación digital de los efectos de las bombas con el fin de aumentar la carga dramática también contribuye a acentuar el componente de ficción en este ejemplo.

Con planteamientos cercanos a los del periodismo de investigación televisivo, heredero de las convenciones propias de la novela y del cine de espionaje, y que exige, por tanto, valores narrativos impactantes (Sánchez-Biosca, 2005: 45), La sombra del iceberg (Hugo Doménech / Raúl Montesinos Riebenbauer, 2008) se centra en la indagación llevado a cabo por sus autores y reflexiona sobre como la famosa foto tomada 
por Robert Capa en Cerro Muriano (Córdoba), posible resultado de una puesta en escena, se constituyó y aún sigue siendo un símbolo del conflicto español.

Un mecanismo narrativo similar se repite, por ejemplo, en Lorca, el mar deja de moverse (Emilio Ruiz Borrachina, 2006), que, centrado en las horas previas y en las circunstancias del asesinato de García Lorca y, destaca el proceso de las investigaciones realizadas tanto por el director como por los historiadores Ian Gibson, Miguel Caballero y Pilar Góngora como elemento esencial de la puesta en escena.

En los tres casos anteriores se trata de una estructura asimilable a la del "viaje del héroe" (Vogler, 2002). Un principio seguido por los guionistas de la ficción audiovisual por el que, para conseguir un buen producto, es conveniente centrarse en el camino de conocimiento que lleva a un personaje bien definido a superar sus conflictos.

Este mismo esquema aparece, por ejemplo, en El honor de las injurias (Carlos García-Alix, 2007), centrado en el anarquista, Felipe Sandoval, alias 'Doctor Muñiz', que, buscando la revolución social, actúa como atracador, delator y pistolero durante la Guerra Civil. La estructura de la narración se construye, aquí, sobre dos procesos vitales que se presentan en un montaje paralelo, que relaciona decisivamente las dos tramas: la evolución del personaje central, que se suicida cuando es detenido en 1939, y los motivos del propio García-Alix para buscar la memoria que ha quedado del anarquista.

No darse por vencido (Susana Arbizu y Henri Belin, 2011) y Emilio, el eco de otros pasos (Enric Miró, 2012) se centran también en dos personajes carismáticos cuya trayectoria está relacionada con la Guerra Española. El protagonista del primer título es Daniel Serrano, un exiliado republicano en Francia que, con 91 años, sigue luchando por rehabilitar la memoria de su hermano, teniente de alcalde en un pueblo Toledo durante el Frente Popular y fusilado en 1941. En el segundo caso, se trata de Emilio Marco, luchador anarquista también exiliado en Francia y muy anciano.

En el documental de Susana Arbizu y Henri Belin, queda más clara una estructura de guión asimilable al "viaje del héroe." De hecho, ante la pasividad de las autoridades españolas, el protagonista incluso se desplaza en persona a su pueblo. A falta de una conclusión satisfactoria para la búsqueda de Daniel, porque en el pueblo no acceden a quitar los símbolos fascistas ni a reconocer la figura de su hermano, los directores le proporcionan una revancha simbólica en una secuencia final en la que se mezclan la reconstrucción dramatizada y el montaje, como en otras secuencias anteriores. Mientras Daniel aparece durmiendo la siesta, en paralelo se desarrollan diferentes planos de un desfile de Semana Santa en su pueblo. En el sueño, alguien ha cambiado el nombre a la calle José Antonio por calle de la República con un graffiti. El último plano de la secuencia y de la película recoge el rostro de Daniel sonriendo.

En una opción bastante más radical que en el caso anterior, el único elemento de continuidad de Emilio, el eco de otros pasos son las conversaciones telefónicas que mantiene el personaje principal y que se añaden en over sobre imágenes de la 
cotidianidad en la que se ve condicionado por su situación de invalidez. El montaje, es, pues, más que la reconstrucción dramatizada, como en No darse por vencido, el elemento preponderante para establecer la trayectoria vital del protagonista de este documental.

Por una parte está la imagen, estructurada en las secuencias de larga duración, dónde los planos, casi siempre fijos y de amplia profundidad de campo, se centran en el limitado horizonte vital del anciano confinado en su casa. El sonido en out del tictac del reloj, presente con mucha frecuencia, contribuye a aumentar la impresión de la lentitud y monotonía que marcan la vida de Emilio. En clarísimo contraste, la fluidez y la viveza de los recuerdos del anciano anarquista y, sobre todo, los que comparte en varias conversaciones telefónicas con un compañero que luchó con él, José Fortuny, que suelen aparecer en muchas ocasiones unidos a secuencias de la vida actual del protagonista.

No hay, pues, en este caso, ninguna línea argumental clara: la historia de Emilio se percibe de manera fragmentaria. No hay tampoco conclusión alguna. El héroe, por tanto, lo es en el documental de Enric Miró no por la actividad que desarrolla o por la evolución que manifiesta, sino por su lucha por mantener la memoria ante los imperativos de la ancianidad y de la muerte.

De manera muy patente en La doble vida del faquir y con la única excepción de Noticias de una guerra, que se aparta por completo de esta tendencia, en estos documentales en los que se da un lugar preponderante a recursos narrativos procedentes de la ficción, también aparece otra tendencia que determina de forma radical otros títulos de no ficción producidos desde 2001 en España: el recurso a las fuentes orales anónimas, que demuestran una gran capacidad inductora para el recuerdo y también para crear una emoción en el espectador muy próxima a la que puede generar en él un personaje de ficción.

\section{Las fuentes anónimas y la recreación de emociones en la estructura narrativa documental}

Es evidente la trascendencia que se atribuye en los ámbitos académicos a los significados generados por la acción comunitaria del grupo social en cada momento, que constituyen la denominada memoria colectiva. Ya desde los años de la transición democrática, con la publicación de la obra de Ronald Fraser (1979), en este país empezó a atribuirse un valor historiográfico creciente a la memoria oral de los individuos anónimos que vivieron la República y la guerra.

Pero, para explicar este uso tan reiterado de las fuentes orales, sobre todo en las producciones audiovisuales habría que aludir también a que, en cuando el espectáculo se ha convertido "en el corazón del irrealismo de la sociedad real" (Débord, 1995: 9), incluso el discurso informativo referido a temas históricos suele definirse por una tensión dramática y emotiva. Y esto acentúa la importancia de los testimonios 
individuales en detrimento de otros mecanismos como la argumentación descriptiva $\mathrm{y}$, aparentemente, aséptica que transmitía la antes predominante voz en over omnisciente en documentales o noticias y reportajes de televisión.

Entre los documentales históricos producidos en España durante la última década en España, se pueden citar diferentes ejemplos que tiene el uso de fuentes orales anónimas como eje exclusivo. La guerrilla de la memoria (Javier Corcuera, 2001) recoge la experiencia de los republicanos que decidieron seguir combatiendo a Franco después de la guerra civil. En Los niños de Rusia (Jaime Camino, 2001), se analiza la peripecia vital de los niños republicanos evacuados a la URSS en la Guerra Civil. Mujeres en pie de guerra (Susana Koska, 2004) se centra en ocho mujeres que participaron en la Guerra Civil, la resistencia contra los nazis durante la II Guerra Mundial en Francia y la oposición contra el Franquismo en España. Los perdedores (Driss Deiback, 2007) focaliza su atención en el papel desempeñado en el conflicto por los soldados musulmanes reclutados por Franco. Y Memorias rotas (La balada del comandante Moreno) (Manane Rodríguez, 2010) trata sobre el recuerdo que se tiene entre la gente de los pueblos cercanos al lugar en el que murieron, en la frontera entre Asturias y Galicia, del fusilamiento de un grupo de soldados republicanos del Batallón Galicia liderados por el anarquista José Moreno.

Por otra parte, se pueden distinguir los ejemplos que utilizan los testimonios supeditadas al hilo conductor de la voz en over omnisciente de un narrador. Es el caso de Extranjeros de sí mismos (Javier Rioyo y José Luis López-Linares, 2000), que se centra en soldados que fueron a luchar fuera de sus respectivos países durante el periodo de entreguerras, como los integrantes de las Brigadas Internacionales y de la infantería italiana alineados con republicanos y franquistas respectivamente entre 1936 y 1939 y los españoles que se unieron a los ejércitos de Hitler en su campaña en el frente soviético durante la II Guerra Mundial. También se ajusta a esta misma fórmula La guerra cotidiana (Daniel Serra y Jaime Serra, 2001), que recoge los testimonios de 22 mujeres de distinta condición social para mostrar distintas circunstancias que determinaban la vida cotidiana durante el conflicto.

Evidentemente, la estructura de los dos documentales citados justo arriba puede atribuirse al deseo de obtener una mejor acogida entre una mayoría de los receptores, acostumbrada a una argumentación sobre el mundo histórico ya previamente construida y absolutamente cerrada cuando se acerca a una producción audiovisual de no ficción.

Conscientes de que la identificación exclusiva que hacen los espectadores con la voz en over de un narrador como eje es tal que puede dificultar, incluso, su aceptación de otras fórmulas diferentes, los directores de los documentales citados en los que no aparece la voz omnisciente toman distintas opciones formales para cohesionar una narración basada en fuentes orales.

En La guerrilla de la memoria, la carencia de un orden claro en la sucesión de los personajes y la falta de recursos formales que aporten continuidad entre unas secuencias y otras llegan a dispersar la atención. En Los niños de Rusia, sin embargo, los 
testimonios expuestos son estructurados con un orden perceptible, debido al recurso que se hace en el montaje a la cronología de los acontecimientos y a algún otro apoyo, como las imágenes de archivo del informativo cinematográfico soviético sobre la declaración de guerra de Hitler a la URSS en 1941.

En este sentido, se puede destacar la opción de Manane Rodríguez para aportar continuidad a Memorias rotas. En este documental el relato avanza a la par que una copla popular sobre el fusilamiento del grupo de soldados liderado por el comandante Moreno que fue compuesta en tiempos de la guerra y que aún sigue siendo cantada por los habitantes de la zona. El Comandante Moreno es un héroe; la copla, un cantar de gesta, pero también una excusa para que los entrevistados introduzcan anécdotas familiares, especulen con lo sucedido y manifiesten abiertamente su opinión.

Palabras de la última generación que puede hablar de la Guerra y de la represión franquista en primera persona y que, a falta de otros elementos como imágenes de archivo, inexistentes, son aportan verosimilitud al relato. También es destacable que los paisajes de la zona en los que se sitúan los acontecimientos narrados aparecen de manera reiterada en planos largos y con sonido ambiente como forma de transición entre diferentes bloques de entrevistas. El espectador relaciona la inmutabilidad del espacio en el que se sitúa la historia con lo que cuentan los testigos que, así, se recarga de veracidad (Roca, 1999: 130).

Sin dejar de lado cómo se destaca en ellos el valor histórico de los testimonios, el uso de las fuentes orales en los documentales considerados muestra una naturaleza ambivalente. Se puede cuestionar hasta qué punto el documentalista muestra a sus fuentes de una manera convenientemente personalizada o, por el contrario, los testimonios se convierten para él en recursos que puede utilizar indistintamente con el único fin de enriquecer el sentido de su discurso o imprimirle mayor legitimidad.

Este es, claramente, el modo de representación que se hace las fuentes anónimas, incluso cuando aparecen como fuentes únicas, como ocurre en La guerra cotidiana, o son protagonistas absolutas de la narración, como en Siempre días azules (Ismael Sánchez-Prieto Crespo, 2005), que contrapone las actitudes de una mujer que sostuvo los ideales republicanos y otra que vivió en el lado franquista cuando ambas se enfrentan al posible descubrimiento de los restos de sus familiares muertos en una fosa común dónde supuestamente fueron enterrados. En estos dos documentales, como en muchos otros, las protagonistas son elementos intercambiables. No hubiera supuesto ninguna diferencia que su presencia hubiera sido sustituida por la de otras que hubieran estado dispuestas a prestar su testimonio.

Además, ya se centren en personas que vivieron circunstancias excepcionales, como los maquis, las mujeres que lucharon por su militancia o los soldados musulmanes reclutados por el ejército de Franco, por poner sólo tres casos, o bien opten por reflejar a personas que experimentaron el acontecimiento en toda su cotidianeidad, en casos más raros como La guerra cotidiana, hay que destacar el impacto emocional como objetivo básico de los documentales históricos españoles recientes que utilizan fuentes orales. 
La muestra más clara de hasta qué punto ese uso de las fuentes orales anónimas para crear emoción en el espectador tiene mucho que ver con la ficción es 30 años de oscuridad (Manuel H. Martín, 2011). En él se usa como eje la figura de Manuel Cortés, alcalde republicano de Mijas (Málaga), que, protegido por su mujer, Juliana, pasó 30 años escondido en su propia casa por miedo a la represión franquista

El uso de los recursos formales de la novela gráfica para reconstruir los episodios de la vida de Cortés, que se muestra como figura representativa de los llamados "topos de la guerra", se aparta ya de manera radical del concepto del documental como reflejo directo del mundo físico y sirve para trasladar las vivencias de Manuel y Juliana con una dimensión metafórica que hubiera resultado imposible de haberse tratado de imágenes de archivo o de reconstrucciones dramatizadas con una puesta en escena convencional, más fácilmente asimiladas a lo verosímil por los espectadores. Es el caso del episodio en el que, durante uno de los muchos registros realizados para encontrarlo, un grupo de guardias civiles son representados con la iconografía asociada a la muerte.

Pero esta dimensión ficticia, se acentúa porque todos los episodios de la vida de los dos protagonistas, recogidos de manera detallada, por ejemplo, en varios libros de Ronald Fraser, aparecen narrados siempre en primera persona con las voces de dos actores muy conocidos, Juan Diego y Ana Fernández, cuyas fisonomías han inspirado también la representación de la que son objeto los personajes reales en los episodios reproducidos con dibujos.

El análisis de un acontecimiento relacionado con la representación franquista se lleva a cabo, pues, en esta película, a través de un protagonista único, Cortes. Esta aproximación a la Historia a través de la experiencia individual que supone 30 años de oscuridad utiliza, además, la imaginación, que sirve para alimentar la memoria porque hace visible lo que de otra manera hubiera quedado desconocido (Roca, 1999: 131), en este caso, la peripecia vital del alcalde de Mijas de la que apenas quedan testimonios gráficos. El tiempo biográfico, pues, da sentido al tiempo histórico social, en el que no se había conservado registro de esa dimensión del acontecimiento porque no pertenecía al relato hegemónico, en este caso el de los vencedores de la Guerra.

Sin embargo, se podría cuestionar también si se está produciendo una perversión en el reflejo de la Historia en estas producciones, en la medida en la que la memoria individual de los testigos se lleva a extremos tan coincidentes con lo ficticio que puede llegar a ocultar lo acontecido en lugar de ayudar a su comprensión.

Sea como sea, no parece que sea el caso de 30 años de oscuridad, en el que los testimonios de especialistas como los historiadores Ronald Fraser o Encarnación Barranquero, por poner dos ejemplos, aportan un conocimiento histórico consensuado que sirven para contrarrestar la dimensión emocional de la peripecia de Cortes y llevan el documental dirigido por Manuel H. Martín a ámbitos narrativos más convencionales.

En el caso anteriormente analizado, el uso preponderante de las fuentes anónimas como eje narrativo se une al uso de recursos narrativos procedentes de la ficción. En 
Mujeres en pie de guerra, que se fundamenta en las fuentes orales, y en el que tanto el protagonismo en los acontecimientos históricos como la identidad individual y de género de las protagonistas aparecen equilibrados, la estructura narrativa también viene determinada por la propia figura de la directora, que hace del documental una búsqueda personal: de hecho, en una clara metáfora, la película se inicia y culmina con dos secuencias en las que se muestra a la directora en un tren y en un coche, respectivamente.

Resulta claro, pues, hasta qué punto los recursos narrativos de resonancias ficcionales aparecen juntos, e incluso fusionados en muchos de los documentales históricos producidos en España en el siglo XXI.

\section{Conclusión: ¿es posible un documental en primera persona del singular?}

Para concluir el cuadro trazado acerca de los recursos de resonancias ficcionales en los documentales históricos, habría que destacar cómo la experiencia individual del realizador ha acentuado su importancia como eje estructurador de documentales recientes considerados de calidad e, incluso, legitimados socialmente de manera bastante mayoritaria. Bucarest, la memoria perdida (Albert Solé, 2009), en el que el director habla de su padre enfermo de Alzheimer, Jordi Solé-Tura, uno de los padres de la Constitución Española de 1978, se produjo, por ejemplo, con la participación decisiva de TVE y ha sido emitido en varias ocasiones por la cadena de televisión pública española. Se podría plantear, pues, si resultan compatibles el conocimiento histórico y la retórica performativa, que convierte esta nueva modalidad documental en el grado máximo de la implicación subjetiva y emocional del realizador.

El uso de recursos de planificación o puesta en escena sin relación expresa con el mundo histórico y, sobre todo, las menciones a la biografía y a las implicaciones emocionales del documentalista con lo que está narrando no eliminan el requisito de veracidad y la relación de confianza entre éste y el espectador.

Por una parte, la puesta en situación del proceso de búsqueda personal del realizador-protagonista de un documental (decisiones y tomas de postura que condicionan la narración) y de sus negociaciones con otros participantes en la película permiten distinguir con claridad entre los elementos de la narración generados intencionadamente por el autor y los testimonios o documentos referidos específicamente al pasado que se retrata.

Además, las funciones simultáneas de narrador y protagonista de quien firma un documental como Bucarest, la memoria perdida o Nadar (Carla Subirana, 2009) diversifican el acceso al conocimiento histórico. El viaje emocional que emprende el director para entender su propia historia materializa de manera especialmente fiel la reconstrucción social del recuerdo. La identidad individual y/o familiar del realizador-protagonista, su verdad narrativa (Spence, 1984), da sentido, por tanto, a la identidad colectiva. 
En los títulos citados justo arriba, tan ilustrativos del documental performativo de carácter histórico, la reconstrucción de la memoria familiar constituye una forma de reconocimiento identitario para el realizador. El abuelo de Carla Subirana, el anarquista Joan Arroniz, muerto en la Guerra Civil y el padre de Albert Solé personifican el 'mito familiar' y son asociados con referentes ficcionales.

Se da, así, la unión del tiempo interior, que expresa la dimensión subjetiva, y del tiempo biográfico, que sirve para dar significado a la vida del sujeto, en este caso los directores de Nadar y Bucarest..., dentro del conjunto de conocimientos socialmente disponibles (Leccardi, 2002: 43). ¿Se puede decir que la unión de estas dos categorías de tiempo ayudan a que el espectador de estos documentales performativos pueda dotar de sentido los acontecimientos históricos?

Aunque debería ser objeto de un análisis más detallado, se puede decir que la performatividad que define Nadar y Bucarest, la memoria perdida sirve como culminación de todo el proceso en el que los documentales históricos españoles más recientes se tiñen con la cualidad de lo ficcional y lo subjetivo a través de diferentes pautas de estilo y recursos narrativos. En definitiva, ya no son las "noticias de una guerra" que mencionaba el título del documental de Eterio Ortega mencionado. Su voluntad referencial parece cada vez más diluida en comparación con el peso que adquieren los elementos ficcionales en su estructura narrativa y en el punto de vista elegido para las cuestiones que reflejan.

\section{Bibliografía}

DÉBORD, G. (1995). La sociedad del espectáculo. Ediciones Naufragio. Santiago de Chile.

FRASER, R. (1979). Recuérdalo tú y recuérdalo a otros. Historia oral de la Guerra Civil española, Barcelona, Crítica.

SALMON, Ch. (2008). Storytelling. La máquina de fabricar historias y formatear las mentes, Barcelona, Editorial Península.

SPENCE, Donald (1984) Narrative Truth and Historical Truth: Meaning and Interpretation in Psychoanalysis, Nueva York, Norton paperback.

VOGLER, Christopher (2002), El viaje del escritor: [las estructuras míticas para escritores, guionistas, dramaturgos y novelistas], Barcelona, Ma non troppo.

LECCARDI, C. (2002). "Tiempo y construcción biográfica en la "sociedad de la incertidumbre": Reflexiones sobre las mujeres jóvenes". Nómadas, Abril, pp. $42-50$

ROCA, L. (1999). "La memoria imaginada. El encuentro del testimonio oral y el visual", Secuencia, nueva época, no.43, enero-abril, pp.127-136.

SÁNCHEZ BIOSCA, Vicente (2005): "Políticas de la memoria. La guerra civil española en el cine y el reportaje televisivo", Archivos de la Filmoteca, no 49, pp. $33-53$. 


\section{Los autores}

Inmaculada Sánchez Alarcón es doctora en Ciencias de la Información por la Universidad Complutense de Madrid desde mayo de 2000. Desde el curso 95/96 imparte clases en la Facultad de CC. de la Comunicación de la Universidad de Málaga Y desde noviembre de 2002 es profesora titular de la asignatura cine informativo y documental del departamento de periodismo de la Facultad de Ciencias de la Comunicación de la Universidad de Málaga.

Dentro de su amplia labor docente ha impartido las asignaturas de Teoría de la información periodística, Historia general de la Comunicación, Análisis Hemerográfico y Cine Informativo y Documental así como los cursos de doctorado Historia del documental latinoamericano o Desarrollo de la estructura del medio cinematográfico en Andalucía.

Ha participado en numerosos congresos y seminarios relacionados con el mundo de la comunicación y el cine como profesora y ponente. Como parte de su experiencia investigadora, se puede destacar que ha ejercido la función de investigadora principal en dos proyectos. El proyecto titulado "La actividad cinematográfica en Andalucía. Estudio de fuentes relativas al periodo de la Transición política (1975-1982)" (Cod. 833/06), que tuvo una duración de 12 meses y que se extendió entre 2006 y 2007, ha recibido la financiación de la Dirección General del Libro y del Patrimonio Bibliográfico y Documental (Consejería de Cultura, Junta de Andalucía). El otro proyecto encabezado por Inmaculada Sánchez tiene por título "Personajes, acciones y escenarios andaluces en el cine español, 1934-2006" (Ref. CULB1.07/075) y ha sido financiado por el Centro de Estudios Andaluces con una duración de 11 meses entre el 1 de febrero y el 30 de diciembre de 2007.

Ha publicado los libros La comunicación social durante el franquismo, en el que ejerció como editora con Juan Antonio García Galindo y Juan Francisco Gutiérrez Lozano, y El cine francés y la Guerra Civil Española, derivado de su tesis doctoral. Otros de sus libros son El cine en Málaga durante la Transición, editado por el Centro de Ediciones de la Diputación de Málaga en 2006 o La imagen de la mujer andaluza en el cine español, editado por el Centro de Estudios Andaluces en 2008. Su aportación más reciente es Doc.21. Panorama del documental reciente en España, aparecido en 2009 y del que es coordinadora y coautora. El objetivo principal del libro, prologado por Román Gubern, es reflejar un panorama exhaustivo sobre el sector de actividad del documental en España durante los últimos ocho años. Igualmente, Inmaculada Sánchez ha elaborado capítulos para diferentes proyectos editoriales relacionados con el cine y la comunicación.

Asimismo posee experiencia en la organización de congresos, seminarios y jornadas. Ha sido la directora del I Curso de Producción y Realización de documentales para cine y televisión, curso de pregrado aprobado por el Rectorado de la Universidad de Málaga y celebrado en la Facultad de CC. de la Comunicación de la Universidad de Málaga entre septiembre de 2005 y enero de 2006. Se trataba del primer curso de 
documentales de entidad universitaria que se ha llevado a cabo en Andalucía, que se prolongó en un curso de experto celebrado durante el curso 2006-2007 y que también fue dirigido por la profesora Sánchez.

Alejandro Jerez Zambrana es Licenciado en Periodismo por la Universidad de Málaga (España) desde junio de 2013. Desde octubre de ese mismo año, es alumno del Máster de Investigación en Comunicación Periodística de dicha universidad con la intención de iniciar su doctorado. En 2010 comienza a colaborar en el grupo de investigación sobre temas audiovisuales de la Dra. Inmaculada Sánchez Alarcón, su profesora de Cine Informativo y Documental.

Ha participado recientemente en el XIX Congreso de Hispanistas Alemanes que tiene lugar cada año en el país germano llevado a cabo en marzo de 2013 en la localidad de Münster. En él, tuvo la oportunidad de compartir ponencia con la Dra. Inmaculada Sánchez sobre temas relativos a la representación de la historia en el documental performativo. En noviembre de 2013, asistirá a otro congreso internacional, esta vez, en Besançon (Francia) con una ponencia sobre el estereotipo cultural en documentales centrada en la figura de Federico García Lorca. Además, es miembro de un proyecto de investigación acerca de Innovación Educativa en la Universidad de Málaga y prepara artículos para el envío a diversas revistas sobre el tema en el que quiere especializarse: la biografía y la autobiografía en el cine documental. 